\title{
Trajetória, avanços e desafios do teatro-educação no Brasil
}

\author{
Arão Paranaguá de Santana
}

O século XX foi palco de mudanças estruturais em todos os setores e ramificações da atividade humana. $\mathrm{Na}$ vasta dimensão do planeta, firmaram-se culturas pautadas na economia industrial e nas descobertas tecnológicas sofisticadas, bem como emergiram, sob novas formas e estágios de desenvolvimento, povos que passaram a garantir liberdades constitucionais, estimular empreendimentos e fomentar intercâmbio político-cultural com organismos e governos de outras regiōes. Enquanto as revoluçōes científicas contribuíram para acentuar as marcas de um período rico em produção de conhecimento, técnicas e práticas, a arte, antes vista como forma de elevação espiritual das elites ou meio de transmissão de lições para as classes desfavorecidas, passou a compor o imaginário cotidiano e ser valorizada no seio da sociedade.

No campo da educação germinaram novas concepções e finalidades para a escolarização, a qual consolidou-se enquanto possibilidade de coesão social, surgindo, em período mais recente, descobertas que apontam para a superação do ensino tradicional consubstanciadas na nova sociologia da educação, na psicopedagogia, na teoria crítica, no multiculturalismo e noutras vertentes que compóem o imenso arquipélago da teoria pedagógica. Esses trabalhos têm contribuído para o avanço de pro- postas teóricas e metodológicas relativas ao ensino e ao aprendizado, possibilitando aos educadores um certo estranhamento para que possam relativizar as diferenças entre os estágios de desenvolvimento material e cultural dos alunos, concedendo-lhes, também, certas estratégias para compreensão de uma modernidade que foi alcançada apenas por pequena parcela da população mundial, embora esteja à vista de todos (Canclini, 1998).

Face a esses fenômenos estampados no tecido social e suas implicações na escolarização, o ensino da arte, hoje, tem procurado romper barreiras historicamente impostas à sua prática concreta, fundamentando-se em obras e conceitos provenientes da arte contemporânea, do fazer dos artistas, do pensar dos críticos, das práticas culturais comunitárias, das propostas de museus e sobretudo da realidade da sala de aula. Contudo, para que se compreenda esse quadro nas suas múltiplas dimensões, torna-se necessário contextualizar a evolução da área abordada nesse artigo - teatro na educação escolar -, seu estado atual e perspectivas futuras, traçando comparações e analisando os desafios mais prementes.

\section{Breve panorama histórico}

Desde o período colonial o teatro vem sendo utilizado como instrumento educativo, embora

Arão Paranaguá de Santana é doutor em artes e professor da Universidade Federal do Maranhão. 
a ação dos padres jesuítas tenha se limitado à catequese, face à impossibilidade de uma atuação mais rigorosa, em termos quantitativos e qualitativos, nas escolas de aprender a ler e contar. Com as reformas do Marquês de Pombal e a expulsão dos jesuítas, o sistema de ensino pouco foi alterado, continuando a educação dos ricos a cargo dos colégios e universidades europeus e a dos pobres relegada a um modelo pedagógico pautado na iniciação à escrita e aprendizado das quatro operaçôes. Predominavam os interesses portugueses na esfera cultural e nem mesmo o ideário iluminista teve repercussão por aqui, pois a difusão de idéias diferentes das preconizadas pelas elites era proibida e as publicações controladas.

A criação da Academia Imperial de Belas-Artes (1816) foi a primeira iniciativa a marcar a ação estatal nesse campo, ganhando uma certa relevância na escola elementar o ensino do desenho geométrico. Algumas décadas depois surgiu o Colégio Pedro II, concebido para ser padrão de organização escolar e de qualidade no ensino médio - na tabela de estudos constavam música vocal, desenho figurado e poética.

Quando dava os primeiros passos rumo à modernização, o teatro nacional ressentia-se da inexistência de artistas e pessoal técnico para a atuação nos palcos, o que levou o ator João Caetano a imaginar uma escola dramática para a cidade do Rio de Janeiro, mas seu empreendimento não foi contemplado seja pela iniciativa privada, seja pelo poder público. Ademais, a instituição escola de teatro seria propagada apenas anos mais tarde, no bojo da revolução cênica que marcou a virada do século no Ocidente, quando o fazer teatral rejeitou a encenação tradicional e exigiu do ator "um longo período de formação, que justifica por si só a existência, em nossos dias, das escolas de arte dramática"
(Bornheim, 1992, p. 21). Essa idéia repercutiu no Brasil, lenta mas progressivamente, através do advento de escolas ou conservatórios teatrais, a partir de meados do século XX.

Sob a égide da pedagogia tradicional, a penetração do teatro na escola consistia somente na comemoração de datas cívicas ou montagem de espetáculos para animar solenidades. Contudo, a partir dos anos 1940, quando o movimento escolanovista difundiu-se em um Brasil que passava por transformações políticas da maior importância e planejava a expansão da escolarização, a arte ganhou um status novo, passando a ser vista como experiência que leva ao aprendizado e ao desenvolvimento expressivo.

As primeiras práticas de teatro-educação surgiram junto às escolinhas de arte de Augusto Rodrigues, disseminando-se aos poucos em colégios experimentais, escolas de magistério etc. Entretanto, como não havia tradição em termos de ensino da linguagem teatral - seja na educação básica ou profissionalizante -, ocorreu a difusão massiva do espontaneísmo, quando não a atribuição à arte do papel de atividade coadjuvante de outras matérias do currículo.

O grande marco na história deu-se com a obrigatoriedade da educação artística no ensino de $1^{\circ}$ e $2^{\circ}$ graus, implementada por lei federal em 1971, prevendo-se a modalidade artes cênicas, para ser ministrada de maneira polivalente junto a música, artes plásticas e desenho, durante cinqüenta minutos por semana, o que se tornou, na experiência concreta da sala de aula, algo de difícil realização. Não obstante, foi a partir da implantação da educação artística que surgiu a necessidade da formação de professores, colaborando decisivamente para a expansão do ensino das artes em nível superior e ocasionando a emergência da pesquisa acadêmica em um campo até então inexplorado. ${ }^{1}$

1 À época da implantação da educação artística não existiam mais de 30 cursos superiores nas diversas áreas, quase todos em âmbito de bacharelado, sendo a maioria de artes plásticas; hoje, há cerca de 350 cursos superiores, sendo que mais de 100 referem-se especificamente a licenciaturas. 
$\mathrm{O}$ ensino superior de teatro foi regulamentado em 1965, embora o Conservatório Brasileiro de Teatro ofertasse, desde 1939, um curso alternativo que não tinha delegação de competência para expedir diploma aos concludentes. A partir da reforma universitária de 1968, ocorreu uma expansão expressiva no ensino universitário de teatro, somando-se atualmente onze bacharelados e vinte e uma licenciaturas nas várias regiōes do Brasil.

Levando-se em conta a inadequação dos currículos praticados por escolas e universidades, fortaleceu-se, durante os anos 1990, um movimento iniciado ainda na década anterior, o qual reivindicava a reformulação do ensino das artes em todos os níveis da escolarização. $\mathrm{O}$ avanço mais significativo dessa jornada efetivouse com a manutenção da obrigatoriedade em todos os níveis da educação nacional, através da promulgação da LDBEN (lei no 9394/96), o que engendrou um processo de discussão pública - divulgação de documentos oficiais em versōes preliminares, crítica de especialistas e entidades para-acadêmicas, contribuição das universidades - e redundou na aprovação, pelo Conselho Nacional de Educação, dos referenciais curriculares da educação infantil e dos parâmetros curriculares da educação fundamental e média (PCN), bem como das diretrizes para os cursos superiores de teatro.

Tendo em vista a orientação expressa na legislação em vigor, as secretarias de educação estaduais passaram a adotar novas diretrizes curriculares para o ensino da arte - em alguns casos dobrando a carga horária semanal ${ }^{2}-$, ao passo que as universidades vêm tentando construir projetos pedagógicos que contemplem reivindicaçōes históricas dos estudantes, docentes e pesquisadores, concebendo projetos pedagó- gicos inovadores, reestruturando currículos, denominação dos cursos etc. Esse movimento está processando uma modificação substantiva na relação entre teatro e educação, possibilitando a emergência de novos paradigmas e instaurando desafios quanto à articulação entre os diversos níveis de ensino, como sintetiza o seguinte fragmento:

"Do ponto de vista epistemológico, se num primeiro momento os fundamentos do teatro na educação foram construídos a partir de questóes dirigidas ou formuladas pela psicologia e educação como áreas capazes de fornecer os indicadores de caminho, hoje, o vínculo com a área de formação [em nível de graduação] através da articulação de questões da história e estética do teatro fornece conteúdos e metodologias norteadoras para a teoria e prática educacional." (Koudela, 2002)

Como a historicidade singular que moldou os elementos constituintes do teatro-educação insere-se no rol das contribuições construídas por profissionais e instituições nacionais, torna-se imprescindível compreender esse temário no contexto das influências de outras culturas e das orientações emanadas por organismos internacionais. Todavia, considerando-se a abrangência de um estudo dessa natureza, privilegiou-se a análise relativa às propostas da UNESCO sobre ensino das artes, haja vista a repercussão que tiveram - e têm - no âmbito das políticas públicas e nas formas de financiamento da educação brasileira.

\section{À guisa de discussão: a legislação brasileira e as propostas da UNESCO}

Em meados do século XX, quando muitas nações tornaram-se autônomas e passaram a garantir

2 No Maranhão, as diretrizes curriculares em vigor estabelecem duas horas semanais para a área de arte, da $5^{\mathrm{a}}$ à $8^{\mathrm{a}}$ série do ensino fundamental; em nível médio, apesar de ser recomendada apenas uma aula semanal no primeiro ano letivo, há uma tendência quanto à ampliação da oferta ao longo das demais séries, inclusive em cursinhos pré-vestibulares, em decorrência da inclusão da área nos vestibulares seriado e tradicional da Universidade Federal do Maranhão. 
constitucionalmente o direito à educação, junto a outras que viviam um processo mais avançado de desenvolvimento, mas que ainda não haviam conseguido ampliar as oportunidades educacionais, a UNESCO recomendou a inserção das artes no currículo da escola básica, o que influenciou decisivamente a história da educação mundial. O estudo de Poveda (1995) registra como se processou a inclusão progressiva da arte no ensino escolar espanhol, ao passo em que há trabalhos evidenciando situações semelhantes em países latino-americanos, caribenhos e africanos (Unesco, 2002).

Até então, no Brasil, a arte penetrava na escola através de atividades ligadas ao desenho geométrico, trabalhos manuais e canto orfeônico, sendo que o teatro e a dança tinham importância menor. Com a promulgação da Lei de Diretrizes e Bases (1961), inseriram-se no currículo da escola fundamental as práticas educativas, nas quais constava a arte dramática. $\mathrm{O}$ passo seguinte foi a obrigatoriedade da educação artística (1971), impulsionando o ensino das artes cênicas em todos os níveis da escolaridade, princípio este reafirmado na LDBEN (1996): “o ensino da arte constituirá componente curricular obrigatório, nos diversos níveis da educação básica, de forma a promover o desenvolvimento cultural dos alunos" (art. 26, $\$ 2^{\circ}$ ).

Observe-se que há relação entre esses fatos históricos e as proposiçôes dos organismos internacionais de incentivo à educação e cultura, veiculadas através de colóquios e periódicos. A título de exemplo, vejam-se as aproximações conceituais entre as propostas publicadas na revista Correio da Unesco e os programas de incentivo à integração da cultura popular ao contexto da escola, como o PRODIARTE e o Projeto Interação, desenvolvidos pelo MEC en- tre os anos 1970-80. Para tornar mais explícita essa argumentação, busca-se analisar, agora, o Encontro de Especialistas de Educação Artística da América Latina e Caribe, realizado pela UNESCO em 2001. Os relatórios apresentados pelos experts tinham o propósito de descrever a situação e as perspectivas da arte na escolarização dos países representados, ${ }^{3}$ e considerando-se que a maioria destes possuía currículos nacionais estruturados, foi dada ênfase à discussão específica de cada área: teatro, dança, música e artes visuais. É importante ressaltar uma das conclusōes aprovadas na plenária final e a semelhança com as diretrizes que regem a educação escolar brasileira na atualidade:

"[...] a área de teatro é importante para o desenvolvimento da criatividade e da capacidade simbólica de crianças, jovens e adultos, sendo também uma forma de abrir as portas da escola para a entrada dos valores da comunidade e suas tradições artísticas e culturais. A ponte entre a sala de aula e instituiçóes comunitárias artísticas e culturais cria relações entre crianças, artistas e produtores culturais. A UNESCO se propõe incentivar a promoção de um ensino/aprendizagem em arte e teatro visando ao desenvolvimento da criatividade das crianças, jovens e adultos, e à apreciação de bens artísticos e culturais. (UNESCO, 2002)"

As recomendações atinentes à educação básica referem-se ao teatro como "área de aquisição e construção de conhecimento na escola" ${ }^{4}$ que deve estar presente no currículo com a "mesma importância que as outras áreas de conhecimento", tendo as seguintes características: 1) na educação infantil e primeiras séries do ensino fundamental o teatro "deveria ser parte da

3 O encontro contou com a participação de representantes da Argentina, Barbados, Brasil, Chile, Cuba, Jamaica, México, Peru e Venezuela, consultores da Finlândia, Canadá e Inglaterra, além do pessoal da UNESCO.

4 A partir de agora, todos os trechos entre aspas referem-se a transcrições do documento elaborado pelo GT-Teatro (UNESCO, 2002). 
área de conhecimento denominada arte, ao lado da dança, da música e das artes visuais, dentro de um programa integrado e interdisciplinar"; 2) na última metade do ensino fundamental e no ensino médio, "o teatro deveria ser considerado como uma disciplina autônoma”. É interessante observar que mesmo sendo fruto de uma discussão multicultural, uma vez que participaram do GT-Teatro representantes da Finlândia, Canadá, Jamaica, Peru e Brasil, há similaridade entre as conclusōes do encontro da UNESCO e a orientação dos PCN, inclusive naquilo que diz respeito às atividades extracurriculares.

No documento elaborado pelo GT-Teatro foram previstos dois modelos de formação de professores, sendo um "com caráter generalista, voltado para a educação infantil e primeiras séries do ensino fundamental, e outro de especialização destinado para as últimas séries do ensino fundamental e ensino médio", tal como ocorre nas universidades brasileiras. As características da formação de professores pleiteada são as seguintes: 1) para a formação inicial de generalistas, a área de teatro "deve compor o currículo em conjunto com as outras linguagens artísticas, reservando-se um mínimo de sessenta horas para cada uma delas"; 2) para os professores leigos ${ }^{5}$ que atuam na educação infantil e primeiras séries do ensino fundamental é prevista a fundamentação em cada uma das linguagens artísticas, através de cursos equivalentes; 3) a formação em serviço deveria incluir oficinas, conferências e seminários "ministrados por professores especialistas e artistas de teatro", bem como a inclusão de programas culturais. Não houve menção específica quanto à formação de professores especialistas em teatro, mas as discussões enfatizaram a necessidade de articulação entre as diversas áreas do saber.

O documento da UNESCO recomenda, finalmente, a adoção de estratégias para imple- mentação do teatro no currículo - tais como participação de pais e membros da comunidade com habilidades em teatro, inclusão de políticas culturais integradas às atividades das escolas, universidades, conservatórios, museus etc. - com o objetivo de ampliar as oportunidades de acesso aos bens culturais, fazendo indicações, também, quanto à estruturação do currículo e experimentação de propostas metodológicas contemporâneas.

Cabe agora tecer alguns comentários acerca das implicaçôes dos avanços conseguidos pela área de teatro junto à educação escolar brasileira. Um dos primeiros desafios a ser enfrentado trata dos desdobramentos da legislação curricular no âmbito dos sistemas de ensino espalhados na vastidão de um país continental, de tal maneira que se promova o desenvolvimento cultural dos alunos na realidade concreta da sala de aula, conforme determina a Constituição. Para isso, há de se dar condiçôes para que a tarefa da formação de professores seja implementada com vigor, através de projetos pedagógicos consistentes. Poderiam ser listados inúmeros obstáculos que impedem o pleno desenvolvimento do ensino da arte e particularmente do teatro - os quais deverão ser suplantados a médio e longo prazo -, pauta na qual incluem-se problemas gerais do sistema educacional, a saber: turmas abarrotadas de alunos, espaço físico inadequado, tempo insuficiente para preparação e desenvolvimento das aulas, má qualidade do material didático, diálogo truncado e falta de parcerias, inexistência ou descontinuidade no aperfeiçoamento profissional, mentalidade servil e avessa à ousadia, baixa remuneração dos trabalhadores da educação.

Contudo, a par das dificuldades, existem instrumentos que podem ser utilizados para a transformação da realidade, e sua apropriação implica na criação de possibilidades de construção do futuro. Com base neles, pode-se almejar

5 A recomendação relativa à capacitação de leigos visou adequar-se principalmente à realidade caribenha, onde os artistas de teatro atuam como professores. 
a mudança que se pretende para a educação básica e superior, tal como atesta o depoimento abaixo, sobre as ressonâncias do documento da UNESCO no Peru:

"Esto ha tenido repercussión en mi pais, porque estamos formando la Comision Nacional de Educación Artística com apoyo del Ministerio de Educación. El Ministro de Educación quiere que el arte sea un área de la estructura curricular e para ello vamos a trabajar com las escuelas que forman professores de arte. Esta es la primera vez que sucede algo asi en nuestro país. Espe- ro que llegue todo a buen término y se inicie una nueva etapa en la educación artística. Seguiré trabajando para ello." (Galvan, 2002)

Como se vê, apesar das diferenças regionais, há uma certa similaridade entre os caminhos trilhados por naçôes em estágios de desenvolvimento semelhantes, fazendo-se necessário empreender estudos comparados em articulação a avaliações internas, para que se possa entender, com maior clareza, as transformações que se operam na realidade da educação brasileira no âmbito do teatro-educação.

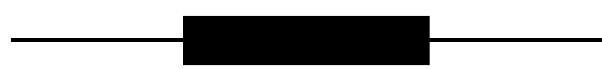

\section{Referências bibliográficas}

BORNHEIM, Gerd. Estudos sobre teatro. São Paulo: Perspectiva, 1992.

CANCLINI, Nestor. Culturas híbridas: estratégias para entrar e sair da modernidade. São Paulo: EDUSP, 1998.

GALVAN, Liliana. Idea latinoamérica [mensagem pessoal]. Mensagem recebida por <anpsant@yahoo.com>.09 abr. 2002.

KOUDELA, Ingrid Dormien. Scientific report on drama/theatre. In: Regional conference on arts education at school level in Latin America and the Caribbean. Disponível em <http://www. unesco.org/culture/creativity/education/html_eng/latam.shtml>. Acesso em: 21 mai. 2002.

POVEDA, Lola. Ser o no ser: reflexión antropológica para un programa de pedagogía teatral. Madrid: Narcea, 1995.

UNESCO. Regional conference on arts education at school level in Latin America and the Caribbean. Disponível em <http://www.unesco.org/culture/creativity/education/ html_eng/latam.shtml>. Acesso em: 21 mai. 2002. 